NASA Technical Memorandum 105255

AIAA-91-3601

\title{
Technology Readiness Assessment of Advanced Space Engine Integrated Controls and Health Monitoring
}

Marc G. Millis

Lewis Research Center

Cleveland, Ohio

Prepared for the

Conference on Advanced Space Exploration Initiative Technologies cosponsored by AIAA, NASA, and OAI

Cleveland, Ohio, September 4-6, 1991 


\title{
TECHNOLOGY KEADINESS ASSESSMENT OF ADVANCED SPACE ENGINE INTEGRATED CONTROLS AND HEALTH MONITORING
}

\author{
Marc G. Millis \\ National Aeronautics and Space Administration \\ Lewis Research Center \\ Cleveland, Ohio
}

\begin{abstract}
NASA Lewis Research Center contracted Aerojet and Rocketdyne to assess the Integrated Controls and Health Monitoring (ICHM) technologies that would enable hydrogen-oxygen rocket engines to be space-based, reusable, and descent-throttleable. The results of these assessments are synthesized to determine the minimum required ICHM functions and system elements, and to estimate the technology readiness and system cost. The minimum functions include preflight checks, tank head start, closed-loop thrust and mixture ratio control with red-line/shutdown safety monitoring, sensor validation/ fault accommodation, and condition assessment. With the exception of the engine-dependent software and some of the advanced sensors, all the required elements have reached at least the technology readiness level of a laboratory demonstration. The total ICHM system readiness is at the level of a conceptual design. The estimated cost to provide a minimum ICHM system ready for demonstration on an engine system testbed is estimated to be $\$ 30$ to $\$ 45$ million over six years.
\end{abstract}

\section{Introduction}

One way to substantially reduce operating costs for rocket engines is to eliminate or substantially reduce maintenance inspections. This can be accomplished by integrating an instrumentation and processing system into the engine controller which can measure and assess the engine's health before, during, and after engine firing. Such an Integrated Control and Health Monitoring (ICHM) system could also improve the engine's reliability by early detection and response to engine degradations and failures.
ICHM is the engine subsystem that controls the engine and monitors the engine's health. It must provide stable and responsive control over the full throttling range, prevent catastrophic engine failure, and reduce or eliminate the need for inspection and maintenance.

A first step toward realizing these features is to select a representative set of mission requirements and then assess the technology necessary to satisfy these requirements. Using the Space Exploration Initiative (SEI) missions as this representative set, this paper answers the following questions about ICHM technology:

(1) What are the minimum ICHM functions and technology elements necessary to satisfy the mission requirements, (2) is it feasible to satisfy the requirements with the currently projected ICHM technologies, and (3) how much will it cost to advance these ICHM technologies to the point were they can be confidently incorporated into the development of next space engine?

To answer these questions, this paper summarizes and synthesizes the results of two different contractor assessments of ICHM technology (ref. 1 $\& 2)$. The synthesis involves combining their results into a single description and using the differences to reflect the uncertainty of the conclusions.

\section{Contractor Assessment Goals}

The contractors, Aerojet Propulsion Division of GenCorp, Sacramento, California, and the Rocketdyne Division of Rockwell International Corporation, Canoga Park, California, were each tasked by NASA Lewis Research Center to (1) specify the minimum functions of an ICHM system capable of meeting a given set of mission requirements, (2) ident- 
ify the necessary system elements to provide those functions, (3) estimate the current technology readiness of each element, and (4) estimate the cost to advance the technology to the level where it is ready for a system demonstration on an engine system testbed. A demonstration on an engine system testbed is considered sufficient technological advancement to confidently proceed with the development of a prototype engine incorporating ICHM. Each contractor was asked to use their own Orbit Transfer Vehicle engine designs as the referenced engine technology.

\section{Mission Requirement Assumptions}

The most applicable mission scenarios that cover the general goal of improving operational efficiency and reliability, plus addressing the issues of in-space engine operations and operational flexibility, are the SEI missions. The advanced space chemical engines for the SEI missions are required to be human-rated, space-based, reusable without major service, and throttleable for descent maneuvers.

The specific mission requirements assumed for this study are based on various studies by the NASA Office of Exploration which describe missions and vehicles for supporting a lunar base. The aspects of these study results that drive ICHM requirements (discussed in ref. 3) were provided to each contractor and are outlined below.

Basic Engine Operation The propulsion system, consisting of 4 engines, is required to be human-rated and fail-operational/fail-safe. This means that the propulsion system must still operate in the event of one failed engine (fail-op) and present no catastrophic hazards to the vehicle in the event of a second failed engine (fail-safe). This translates to using a shutdown response to a failure within an engine, and having the capacity for engine-out operation of the propulsion system. The single-engine reliability is quantified as having a 0.9975 probability of completing the mission.

Because these engines will be used for space transfer, they must be capable of starting in zero gravity. This is accomplished by assuming the use of a tank head start for the engines.

Reusability Reusability means sustaining reliability without major service. This is quantified as having a service-free life of 100 starts with 4 hours total firing duration. This is based on a 5 mission life times a factor of 4 as a safety margin.

Space-Basing The space-basing assumptions are that there would be no in-space facilities to routinely inspect the engine, and that the entire engine would be the in-space replaceable unit.

Descent Throttling A 10:1 throttling range (from 100\% to $10 \%$ thrust) is assumed. No guidelines were available for specifying the throttling response-time requirements for the engines.

Product Evolution Since the mission studies assumed that one engine would be used for the variety of vehicles, a certain degree of flexibility for product improvement is required to be designed into the engine.

\section{Referenced Engine Technology}

The baseline engine from the mission studies is a throttleable cryogenic hydrogen-oxygen expander-cycle rocket engine that is designed for high performance (high specific impulse and long life), reusability, human-rating, and space-basing. The thrust level is designated to be approximately 90 to 111 kilo-Newton $(20,000$ to 25,000 pounds) thrust, and have a throttling range of approximately 10:1 for lunar descent maneuvering.

With the exception of the maximum thrust rating, these characteristics are identical to the requirements of the Orbit Transfer Vehicle Engines for which both Aerojet and Rocketdyne completed preliminary designs (contracts NAS3-23772 and NAS3-23773). Each contractor was tasked to use their 
preliminary design as the reference around which to specify the ICHM system. The engine descriptions are included with each of the ICHM assessment reports (ref's $1 \& 2$ ). The Aerojet design is a $34 \mathrm{kN}$ (7500 1b) thrust dual-expander engine, and the Rocketdyne design is a $34 \mathrm{kN}$ (7500 lb) thrust full-expander engine. Rocketdyne states in their report that all conclusions based on the $34 \mathrm{kN}$ (7500 1b) engine would be equally valid for a $90 \mathrm{kN}(20,000 \mathrm{lb})$ engine.

\section{Minimum Required ICHM Functions}

Based on the mission requirements, both contractors derive similar lists of minimum ICHM functions and features. To avoid confusion from the different terms and arrangements of each contractor's list, the lists are synthesized into the single list presented below. The four major functional areas are: engine control, safety monitoring, diagnostic monitoring, and condition assessment. This synthesis contains all the pertinent items from either contractor, and in those cases where only one contractor proposed a function, that difference is mentioned. Where applicable, references are cited for functions that are discussed more thoroughly in other references.

\section{Engine Control}

Normal engine operation spans several phases that are summarized below. A complete list of phases and the associated status of the control and monitoring functions is detailed in the Aerojet report (ref. 1).
A. Prestart Checks
B. Start Sequence
1. Chill-down
2. Tank Head Ignition
3. Tank Head Idle
4. Pumped Idle
C. Main Stage
1. Proportional Throttling
Control (closed loop on chamber pressure)
2. Proportional Mixture Ratio Control (closed loop on flow)

D. Normal Shutdown
1. Throttle Down

2. Post-firing Safing
E. Dormancy
F. Engine Replacement

Prestart Checks The prestart checks involve powering up the ICHM system and performing built-in tests plus some degree of assessing the condition of the engine using data from the previous firing and using the sensor outputs during the engine's start sequence.

Although both contractors include prestart checks as one of their ICHM functions, a more in-depth study was conducted under NASA contract (ref. 4) in parallel with these assessments to identify and compare various methods for performing automated prestart readiness checks. These methods span a range from actual test-firing to an entirely static checkout (no physical cycling of any components). The technology readiness and remaining development cost of these methods is outlined in this study. (At the time of writing this paper, no conclusions were yet available.)

Start Sequence The tank head start sequence involves phases to satisfy the requirement of a zero-gravity engine start. The duration of this sequence varies, but it can take several seconds. Note that a chill-down phase is required which is accomplished by venting cryogenic propellants through the engine prior to ignition.

Main Stage To provide mission profile and propellant utilization flexibility, both the thrust and mixture ratio are continuously variable, rather than having discrete designpoint settings. This is accomplished by using multi-variable closed-loop control of thrust and mixture ratio based on the feedback from combustion pressure and propellant flow, respectively. Other parameters such as valve positions or temperatures may also be required in the feedback loops. Depending on engine design, other parameters may also be subject to closed loop control, such as the control of the oxygen turbine inlet temperature in the case 
of the Aerojet dual-expdnder engine.

Shutdown The time to go from full thrust to zero thrust may be as long as two to three seconds because of the large residual propellant volumes downstream of the main shutoff valves (ref. 1). After the engine is at zero thrust, the engine is vacuum purged and the actuators are set to safe positions for dormancy.

Dormancy Assuming that the engines will be space-based and reusable, another phase of engine operation is the dormancy period when the engine is not used. Both contractors specify that heaters are required to prevent degradation of the electronics during this period. No other specifics are addressed concerning possible engine degradations from long term exposure to the hazards of the space environment.

Space hazards were inventoried under a separate grant to the University of Cincinnati (ref. 5). This study identifies the types and relative magnitudes of space hazards in the lowEarth-orbit (LEO) to lunar space regimes. The specific effects that these hazards would have on rocket engines have not yet been determined.

Engine Replacement Another operational phase, assuming the engine is space-based, is the replacement of an engine in a vehicle and the associated checks to insure the integrity of this installation. Neither contractor details the impacts of this phase other than through the regular prestart checks.

\section{Safety Monitoring}

For the safety of the crew and vehicle, critical parameters of the engine's operation are monitored. If these parameters exceed preset red-line values, the engine will be immediately shutdown to prevent catastrophic failure. Both contractors specify using this red-line/shutdown method for safety monitoring. In addition, both contractors specify the use of sensor validation and fault accommodation as a minimum feature. Sensor validation/ fault accommodation refers to methods that check sensors for erroneous outputs, and if detected, remove that sensor's output from the control logic. Either redundant sensor data or analytical redundancy replaces that sensor's output.

An additional feature to the above described red-line method is the capacity for condition-dependent red-lines. Condition-dependent red-lines are values that change depending on the operational phase of the engine. Since only one contractor, Aerojet, specifies having this feature, this feature is considered only a candidate minimum requirement. Aerojet proposes to provide this feature by separating the control and monitoring computers in the control architecture. The monitoring computer sets the red-line values depending on engine conditions, and the control computer uses the red-line values in the usual manner.

Another aspect of safety monitoring is engine-out accommodation. In the event of one failed engine, the remaining engines in the propulsion system must either throttle-up or shutdown to maintain the vehicle's thrust balance. This requires having the capacity to initiate a synchronized emergency shutdown of a healthy engine and a synchronized throttle-up of the remaining engines.

\section{Diagnostic Monitoring}

"Diagnostic monitoring" is the realtime monitoring of engine performance to detect off-nominal performance and to possibly adjust the controls to ensure that the engine can complete the mission. This implies real-time detection and identification of engine failures and degradations, and having control options to respond to these failures and degradations. This degree of control sophistication is sometimes called "adaptive control."

This function is only proposed by one contractor, Aerojet, and thus it is considered only a candidate minimum requirement. 


\section{Condition Assessment}

"Condition assessment" is the term used to refer to the process of collecting and analyzing the engine data after a firing to identify degradations, identify anomalous performance, and to possibly estimate the remaining life of the engine. Both contractors leave open the option of where this function is performed; on the vehicle or on ground-based computers. This function is sometimes referred to as "post-flight" or "post-hot-fire" analysis.

\section{Minimum ICHM System Elements}

With the exception of certain sensor technologies and the degree of functional sophistication of the software, both contractors propose similar lists of ICHM system elements. These elements are summarized into the following categories: architectures, electronics, sensors, control effectors, and software. Rather than providing a single synthesized list, the proposed elements from both contractors are summarized here to indicate the span of possible methods for providing the minimum functions.

\section{Architectures}

"Architecture" refers to the configuration and interconnections of the ICHM system components. Aerojet and Rocketdyne both use modular architectures with more than one processor, but configure the architecture of these processors differently. Both contractors provide at least dual-redundancy for the electronics in their architectures. Simplified versions of the Aerojet and Rocketdyne architectures are shown in Figures 1 and 2, respectively. In both reports architectures are provided at the system level, and more detailed schematics are provided for the engine controller electronics.

Aerojet patterned their ICHM system after their AREC II (Advanced Rocket Engine Controller) (ref. 1). This system consists of three backplane buss channels which provide dual redundancy for all circuitry, and triple redundancy for the control and monitoring processors. Two of the channels are identical and each contain a processor for the control functions, a processor for the monitoring functions, and circuits that interface with the other channels, the sensors, the effectors, the vehicle and telemetry bus, the control and instrumentation bus, and the optical disk data storage device. The third channel contains control and monitoring processors, the interchannel interface circuits, and circuits that interface with some of the sensors. Pre-processors are proposed for the more advanced sensor systems such as the plume spectrometer and leak detectors, and some signal conditioning circuits are resident within the bearing deflectometers and shaft deflectometers. To accommodate the large amount of data collected by this system, an optical disk is also proposed.

Rocketdyne uses a dual redundant architecture with dual sets of separate, self-checking, processors for the input, control, and output functions. These processors are linked via dual redundant busses. The input processor provides signal conditioning, digitizing, and sensor validation/accommodation to provide valid sensor data to the control processor. The control processor receives data from the input processor, commands from the vehicle, and performs control and monitoring functions that provide the engine actuator commands to the output processor. The output processor contains the drivers and feedback processing to command and verify the status of all the engine's control actuators.

\section{Electronics}

Aerojet specifies using Intel 180960 based 32 bit RISC processors, MULTI-BUS II backplanes, and a MIL-STD-1553 type bidirectional digital interfaces. Aerojet also provides specific choices for the variety of interface circuits. Rocketdyne does not specify the exact components that would be used, but does list candidate components that are similar to Aerojet's selections. 


\section{Sensors:}

Both contractors specify sensors for measuring temperature, pressure, vibration, flow, actuator position, and pump speeds. The number and type of sensors for both the Aerojet and Rocketdyne systems are listed in Table I. With the exception of Aerojet's larger number of sensors for the actuators and their extra advanced sensors, both contractors have roughly 50 to 60 sensors in each of their systems. Aerojet further specifies which sensors are duplicated for redundancy. Rocketdyne does not specify which sensors would be duplicated for redundancy because they require more definition of the operating requirements before they can specify redundancies.

Aerojet also proposes using some newer sensors to augment the traditional sensor set. These included a FabrePerot interferometric plume spectrometer, two unspecified sensor systems for sensing oxygen and hydrogen leaks, capacitance type three-axis shaft deflectometers for the turbopumps, and capacitance displacement bearing deflectometers. Along with each of these advanced sensors are associated data processing or signal conditioning electronics.

Rocketdyne specifies more advanced sensor technology for pressure and actuator position measurement. They specify silicon-on-sapphire (SOS) pressure transducers and position resolvers over the more mature strain gage pressure transducers and linear-variabledifferential-transformers (LVDT). The SOS technology offers higher accuracy, wider range, longer-term stability, and higher temperature tolerance than the conventional alternatives. Rocketdyne also proposes using eddy current sensors instead of limit switches. As alternative technologies, Rocketdyne lists the more conventional pressure transducers, LVDTs, and limit switches in their sensor list.

\section{Control Effectors}

Both contractors specify using electro-mechanical actuators (EMA) with DC motors for valves, gimballing, and nozzle extension/retraction. Rocketdyne additionally specifies a pneumatic back-up for their EMAs to effect a fail-safe engine shut-down in the event of an EMA failure. Both contractors use spark igniters, and Rocketdyne listed plasma torch igniters as an option.

The type and quantity of control effectors is outlined in Table II. Aerojet specifies 6 proportional and 6 on/off valves, while Rocketdyne specifies 3 proportional and 5 on/off valves. The reason behind the greater number of valves in the Aerojet system is partly due to their choice of the dual-expander engine cycle.

Aerojet also proposes an additional gimbal actuator for engine-out compensation.

\section{Software}

The categorization of the software elements parallels the synthesized ICHM functions presented earlier. An abbreviated list of software elements is provided below:

Engine Control:

A. Prestart Checks

B. Start Sequence

C. Main Stage

1. Proportional Throttling Control

2. Proportional Mixture Ratio Control

D. Normal Shutdown

1. Throttle Down

2. Post-firing Safing

E. Dormancy

F. Engine Replacement Integrity Check

Safety Monitoring

A. Red-line/shutdown Monitoring

B. Condition-dependant Red-lines

C. Sensor Validation/Fault

Accommodation

Diagnostic Monitoring

A. Performance Failure

Identification/Accommodation

B. Component Failure

Identification/Accommodation 


\section{Condition Assessment}
A. Data Management
B. Engine System
Failure/Degradation Identification
C. Component Failure/Degradation
Identification

of these functions, each contractor lists the sensor inputs and commands that are required to perform each function. Three examples; throttling control, mixture ratio control, and redline monitoring, are summarized next.

During main stage, Aerojet controls 2 valves for throttling using the feedback from 3 sensors: combustion pressure and 2 valve positions. Rocketdyne controls one primary valve for throttling using feedback from 2 sensors: combustion pressure and valve position. In both systems, other valves are also adjusted to balance the cycle during thrust and mixture ratio changes.

For main stage mixture ratio control, Aerojet controls 2 valves using the feedback from 8 sensors: 2 flows, 2 temperatures, 2 pressures, and 2 valve positions. Rocketdyne controls one primary valve using feedback from 4 sensors: 2 flows and 2 valve positions.

For red-line monitoring, Aerojet monitors 11 items based on the inputs from 51 sensors, and Rocketdyne directly monitors 8 red-line sensors.

Because a complete engine design is a prerequisite for further software descriptions, neither contractor details the software or algorithms that would be used to answer each function. Aerojet does, however, specify using a UNIX based derivative for the operating system, with Ada code. Expert systems written in Ada code are listed for the diagnostic executive, the preflight readiness, the sensor failure identification, the performance failure identification, and the component failure identification programs. Rocketdyne states that much of the software could be based on the existing SSME software, the SSME Block-II controller software, and the RS-44 engine software.
Because of Aerojet's conditiondependent red-lines, real-time diagnostics, the possibility for adaptive control, and the extra sensors, the magnitude of the Aerojet software is larger than the Rocketdyne software.

\section{Discussion of Differences in Contractor Minimums}

Based on the mission requirements, both contractors derive similar lists of minimum ICHM functions and features, but each propose different approaches to provide these functions. Some of these differences span a range of capabilities or technical maturity. This indicates that there is a reasonable certainty about what ICHM functions are required, but there are a variety of ways to provide these functions.

The most noticeable differences in capabilities are the use of conditiondependent redlines, the possibility for adaptive control, and the inclusion of advanced sensors, which are all exclusive to the Aerojet system. Aerojet states in their report that these features and sensors are included as minimum features to address the substantial reliability requirement associated with reusability and zero maintenance, and to provide the necessary flexibility to accommodate mission variations and product improvements.

To leave open the option of including these extra features, the synthesized list of minimum functions and features presented earlier includes the extra features of the Aerojet system. As more definition of the missions, vehicles, and engines become available, the exact characteristics of the ICHM system can be refined to reflect those specifications.

\section{Technology Readiness Estimates}

Both the proposed systems require more advanced technologies than those used in the existing Space Shuttle Main Engine (SSME) or the RL-10. Both study contractors use more than one processing unit in their architecture; use multi-variable, closed-loop control for 
continuously variable thrust and mixture ratio; use sensor validation and fault accommodation to address the potential problem of a failed sensor; use EMAs for valves and gimballing; and use some of the newer software techniques, such as expert systems, for some of the fault and degradation detection functions.

To provide a more accurate assessment of the level of technical maturity for these minimum ICHM technologies, the contractors assessed the technology readiness of all their system components using the same rating scale that is used by the NASA Office of Exploration (described in ref. 3). This scale provides a consistent baseline for comparing the maturity of various technologies.

The contractors' assessments have been summarized into the following categories: system configuration, sensors, control effectors, electronics, and software. Their results have been synthesized to remove the ambiguities caused by the different interpretations of the readiness scale. A short statement about the next steps to advance each category of technology to the next readiness level has also been added.

In general, both Aerojet's and Rocketdyne's estimates of the technology readiness are about equal. Their assessments conclude that all the required technologies have already been demonstrated in the $1 \mathrm{ab}$ or in similar applications, with the exception of the advanced software and system integration which have reached the level of proof of concept. The magnitude of the remaining work is reflected by the cost estimates discussed in the next section.

\section{System Configuration}

System integration technology has reached at least the level of conceptual design and perhaps as high as having been demonstrated in the lab, depending on interpretation of the terms used in the rating scale. The systems described in the Aerojet and Rocketdyne reports constitute concept- ual designs. A software simulation of either of these systems that takes into account a dynamic engine model and characteristics of the sensors, effectors, and interconnecting electronics would constitute a proof-ofconcept demonstration. An on-engine test of a breadboard ICHM system, including actual sensors and effectors would constitute having demonstrated a system in a relevant environment.

\section{Sensors}

Many of the required sensors are already used in space flight systems, and most of the advanced sensors have reached at least the level of a laboratory demonstration. Some of the more advanced sensors have also been tested in relevant environments. Further sensor advancement typically requires the application of laboratory-proven sensors into relevant environments such as rocket engine component test stands.

\section{Contro1 Effectors}

EMAs have been demonstrated in the $1 \mathrm{ab}$ and in other aerospace applications. The valves for this class of 10:1 throttleable, hydrogen-oxygen engines have at least been conceptually designed. Some of the simpler valves are more mature, being based directly on valves used in similar applications. Further EMA advancement for space engines may only require the application of EMA technology to a representative testbed engine.

\section{Electronics}

All the specified electronics are used in other applications, and thus are considered to be at the level of a lab demonstration or higher. Further advancement of the electronics only requires the application of this technology to a representative testbed engine.

\section{Software}

Software technology has either been conceptually designed or reached the level of proof of concept, depending on the specific function. Software tech- 
nology is less advanced than the other technologies mainly because further software development requires a specific engine design and ICHM system configuration as a prerequisite. For example, complete engine models are required to design control methods such as gains and valve schedules and to guide failure modeling. Specific engine failure mode and effects analysis (FMEA) and test data would also be useful in refining failure and degradation detection software. Both contractors state that specific engine designs were necessary prerequisites to advancing ICHM software.

\section{Cost Estimates}

\section{Total System Cost}

The cost to provide a complete ICHM system ready for testing on an engine system testbed is estimated to be between $\$ 30$ and $\$ 45$ million. This requires a six year technology development period. The cost estimate includes all sensors and effectors which are normally considered as part of the engine cost. This estimate does not include the cost of testing the ICHM system on a testbed engine, but Rocketdyne specifies that a representative test series would include 17 tests of 300 seconds duration each.

To estimate the cost to add an ICHM system to a given engine it would be necessary to subtract the cost of all sensors, valves, actuators, and electronics that already exist on the engine. Depending on the engine choice, this could substantially reduce the cost of the ICHM system.

Another important aspect of the cost of an ICHM system is the potential savings from having an ICHM system during the technology development program. Since the ICHM system is designed to prevent catastrophic failures, the ICHM system can repeatedly save the cost of replacement engines and facility repairs. The ICHM system is also designed to reduce or eliminate inspections and could be used to minimize unnecessary maintenance inspec- tions, further reducing the cost of the engine technology development program.

\section{Range and Uncertainty of Cost Estimates}

The span of $\$ 30$ to $\$ 45$ million in the estimates reflects both the differences in the individual contractor estimates, and the level of uncertainty within each estimate. Both Aerojet and Rocketdyne state a possible error band of $+/-158$ (approx. +/- $\$ 6 \mathrm{M}$ ) exists within their estimates.

The differences between the individual estimates are due to the additional costs of Aerojet's more advanced sensors and software, and Rocketdyne's larger estimate for electronics. Aside from these differences, the cost estimates from both contracts are approximately equal and thus reflect a reasonably representative estimate.

The estimate for the cost of comparable electronics is significantly different between the two contractors. Aerojet estimates about \$8M for their electronics (not including the advanced sensor electronics), and Rocketdyne estimates about $\$ 26 \mathrm{M}$ for electronics. This is a considerable difference. Aerojet has a more detailed listing of the electronic components, and the Rocketdyne estimate is based on experiences with the Block II SSME controller. Other than this distinction, there is not enough information in the reports to objectively determine the reasons behind this difference.

\section{Itemized Costs}

The cost estimates are broken down into the following four categories: sensors, control effectors, electronics, and software. By filtering the contractor results into these categories, separating out costs for Aerojet's more advanced features, and separating out the major cost difference on electronics, a synthesized break down of costs becomes: sensors, \$1M; control effectors, \$13M; electronics, \$8M; and software, \$6M. Adding advanced sensors would add about $\$ 4 \mathrm{M}$, and adding more sophisticated software would add about 
another $\$ 4 M$.

The advanced sensor estimate is derived by isolating the costs of the sensors and electronics associated with Aerojet's advanced sensors. The advanced software estimate is derived by subtracting Rocketdyne's estimate for the more basic software from Aerojet's estimate for a more advanced software package.

The difference in system cost from adding more advanced sensors and software is relatively insignificant compared to the span of the total cost estimate ( $\$ 8 \mathrm{M}$ versus $\$ 15 \mathrm{M})$, indicating that cost may not be the major driver to selecting the required degree of capability for a complete ICHM system.

The distribution of costs for the synthesized estimate, the Aerojet estimate, and the Rocketdyne estimate are shown in the pie charts of Figures 3,4 , and 5, respectively.

\section{Other Findings}

\section{High Speed Turbopumps}

The most critical components for condition monitoring are the high-speed turbopumps (speeds greater than 70,000 rpm). The sensors and algorithms associated with monitoring high speed bearings, seals, and shaft dynamics are critical elements of an ICHM system for this class of engine. Rocketdyne addresses this subject by suggesting the use of newer software techniques, and Aerojet addresses this subject by suggesting the use of three-axis shaft deflectometers, bearing deflectometers, and advanced software.

\section{Vehicle Interface Assumptions}

Since the engine's ICHM system is a subset of the entire vehicle's control and monitoring system, one aspect of the ICHM system is the vehicle interface. Both Aerojet and Rocketdyne use virtually identical assumptions for the vehicle interface. These assumptions are listed next.
Vehicle Propellant System For compatibility with this class of engines, the propellant tanks are assumed to have the following characteristics:

(1) Pressure regulation is provided by the vehicle.

(2) The vehicle supplies the inlet propellent valves.

(3) Propellant tanks are pressurized using autogenous gas supplied from the engine.

Vehicle Electrical Power Twentyeight volt direct current electrical power was assumed to be provided by the vehicle and have the following characteristics:

(1) During periods where the engines are not being used, continuous power will be required for heaters to prevent deterioration of the electronics.

(2) Immediately prior to, during, after engine operation, modest power will be required to drive the ICHM electronics. The ICHM system shall have its own power regulators.

(3) Immediately prior to, during, and immediately after engine operation, intermittent power will be required to drive all engine EMAs and other control effectors.

Vehicle ICHM Communication Communication between the vehicle and the ICHM system will be via a triple redundant connection to a bidirectional digital bus, such as MIL STD 1553B. The ICHM system will provide engine status to the vehicle and all data through the vehicle for telemetry. It is assumed that the vehicle system provides the following commands:

(1) Start-up and shutdown commands

(2) Thrust level

(3) Mixture ratio

(4) Gimbal angle

(5) Nozzle position

\section{Summary of Conclusions}

Based on the results of the Aerojet and Rocketdyne assessments, it appears to be feasible to provide the technology to meet the ICHM needs of projected SEI missions. The mission 
requirements are assumed to include: human-rating, space-basing, fivemission reusability without major service, and lunar descent throttling control. It is estimated that such an ICHM system could be ready for testing on an engine system testbed within six years and for a cost between $\$ 30$ and $\$ 45$ million.

The cost estimate includes many components which are normally considered part of the engine cost (sensors, valves, and actuators), and thus the actual added cost of the ICHM system may be less than $\$ 30-45$ million. The cost differences of adding the more advanced features or sensors is relatively insignificant compared to the span of the cost estimates.

Another aspect of the ICHM system costs is the potential savings from having an ICHM system. Every time the ICHM system prevents the catastrophic failure of the testbed engine it saves the cost of a replacement engine plus the cost of repairing the test facility. Further savings could be realized by using the ICHM's condition assessment function to minimize unnecessary maintenance inspections.

The minimum required functions include: nominal engine control encompassing preflight checks, a start sequence that includes chill-down and tank-head start, main stage with proportional thrust and mixture ratio control; safety monitoring using condition-dependent red-line/shutdown methods, plus sensor validation/fault accommodation; real-time diagnostic monitoring with the option for adaptive control; and post-firing condition assessment to detect component degradations. Of these functions, the condition-dependent feature for redlines and real-time diagnostics with the option for adaptive control are candidate features.

To provide these functions, technology that is more advanced than that used in existing flight-proven rocket engines is required. These include: modular architectures with multiple 32 bit processors, closed-loop multi- variable proportional control for at least the thrust and mixture ratio, sensor validation/fault accommodation, and the use of EMAs.

In addition, the following sensor technologies may be minimally required: silicon-on-sapphire pressure and position sensors, a plume spectrometer, bearing deflectometers, turbopump shaft deflectometers, and distributed hydrogen and oxygen leak detection systems.

With respect to mission and vehicle planners, the noteworthy items include: The engine's chill-down phase involves propellant dumping; a tank head start was assumed for the engine which requires a few seconds to reach full thrust; the shutdown may take 2 to 3 seconds to reach zero thrust; electrical power is required from the vehicle to run EMAs during engine firing and to run heaters in the electronics during dormant periods; propellant tanks are assumed to be autogenously pressurized by gas from the engine; and a MIL-STD 1553B or similar bus will be used for communication between the engines' and the vehicle's control and monitoring systems.

Virtually all of the technologies required to provide the minimum ICHM system have reached at least the level of a laboratory demonstration and some are in use today in other systems. The least mature of the technologies are the advanced sensors, the software, and system integration. Further sensor advancement typically requires the application of the sensors into a relevant environment. Further software advancements require specific engine designs as a prerequisite. System integration would be satisfied by building an ICHM system and testing it on an engine system testbed.

Topics that still remain to be fully addressed include preflight assessment methods, automated methods to verify the integrity of an in-space engine installation, and methods to monitor or compensate for long term exposure to space hazards. 


\section{References}

(1) Bickford,R.L., Collamore,F.N., Gage,M.L., Morgan,D.B., \& Thomas,E.R., "Orbit Transfer Rocket Engine Integrated Control and Health Monitoring Technology Readiness Assessment, Final Report, Task E.7", Aerojet Propulsion Division, Sacramento, CA, 1991, NASA CR-187122.

(2) Cannon, I.,Balcer,S.,Cochran,M., Klop,J., \& Peterson, S., "Definition, Technology Readiness and Development Cost Estimate of the OTVE Integrated Control and Health Monitoring System Elements", RI/RD91-150Task-E.6, Rockwell International Corp., Canoga Park, CA, 1991, NASA CR187123 .

(3) Millis,M.G., \& Binder,M.P., "Integrated Controls and Health Monitoring for Chemical Transfer Propulsion", AIAA Paper 90-2751, July 1990 (Also, NASA TM-103185).

(4) Erickson,C.M., Pauckert,R.M., \& Hertzberg,D.W., "Automated Preflight Methods for Space-Based Rocket Engines", AIAA Paper 91-3603, Rockwel1 International Corp., Canoga Park, CA, September 1991.

(5) Bahr,G., Disimile,P., \& Jones,B., "Space Vehicle Propulsion Systems: Environmental Space Hazards", AIAA Paper 90-1881, University of Cincinnati, July 1990. 
TABLE I.

SENSOR TYPES AND QUANTITIES

\begin{tabular}{|c|c|c|c|c|}
\hline \multirow{2}{*}{ MEASURAND } & \multicolumn{2}{|c|}{ AEROJET } & \multicolumn{2}{|c|}{ ROCKETDYNE } \\
\hline & QUANTITY & TYPE & QUANTITY & TYPE \\
\hline cryogenic temperature & 4 & platinum RTD & 16 & RTD \\
\hline other temperature & 17 & K-thermocouple & 0 & --- \\
\hline pressure & 15 & strain-gage & 15 & $\begin{array}{l}\text { silicon on } \\
\text { sapphire }\end{array}$ \\
\hline vibration & 2 & piezoelectric & 4 & piezoelectric \\
\hline flow & 2 & vortex sheding & 2 & turbine \\
\hline actuator position & 16 & limit switch & 6 & eddy current \\
\hline actuator displacement & 10 & LVDT & 3 & SOS resolver \\
\hline effector current & 5 & inductive & 4 & not specified \\
\hline pump shaft speed & 5 & capacitive & 4 & $\begin{array}{l}\text { variable } \\
\text { reluctance }\end{array}$ \\
\hline pump shaft deflection & 9 & capacitive & 0 & --- \\
\hline bearing deflectometer & 4 & capacitive & 0 & --- \\
\hline plume spectrometers & 1 & interferometer & 0 & --- \\
\hline leak detection system & 2 & not specified & 0 & --- \\
\hline TOTAL \#\# OF SENSORS & $\begin{array}{c}92 \\
\text { (118 with } \\
\text { redundancy) }\end{array}$ & & 54 & \\
\hline
\end{tabular}

TABLE II.

CONTROL EFFECTORS

\begin{tabular}{|c|c|c|c|c|}
\hline \multirow[t]{2}{*}{ CONTROL ELEMENT } & \multicolumn{2}{|c|}{ AEROJET } & \multicolumn{2}{|c|}{ ROCKETDYNE } \\
\hline & QUANTITY & TYPE & QUANTITY & TYPE \\
\hline proportional valves & 6 & EMA pintle & 3 & $\begin{array}{l}\text { EMA sector } \\
\text { ball }\end{array}$ \\
\hline on/off valves & 2 & EMA ball valve & 2 & $\begin{array}{l}\text { EMA venturi } \\
\text { ball }\end{array}$ \\
\hline on/off valves & 4 & solenoid poppet & 3 & $\begin{array}{l}\text { solenoid } \\
\text { poppet }\end{array}$ \\
\hline gimbals & 4 & $\begin{array}{l}\text { EMA linear } \\
\text { actuator }\end{array}$ & 2 & $\begin{array}{l}\text { EMA linear } \\
\text { actuator }\end{array}$ \\
\hline nozzle extend/retract & 1 & EMA ball screw & 1 & EMA \\
\hline igniters & 1 & spark lighter & 2 & spark igniter \\
\hline TOTAL \# OF EFFECTORS & 18 & & 13 & \\
\hline
\end{tabular}




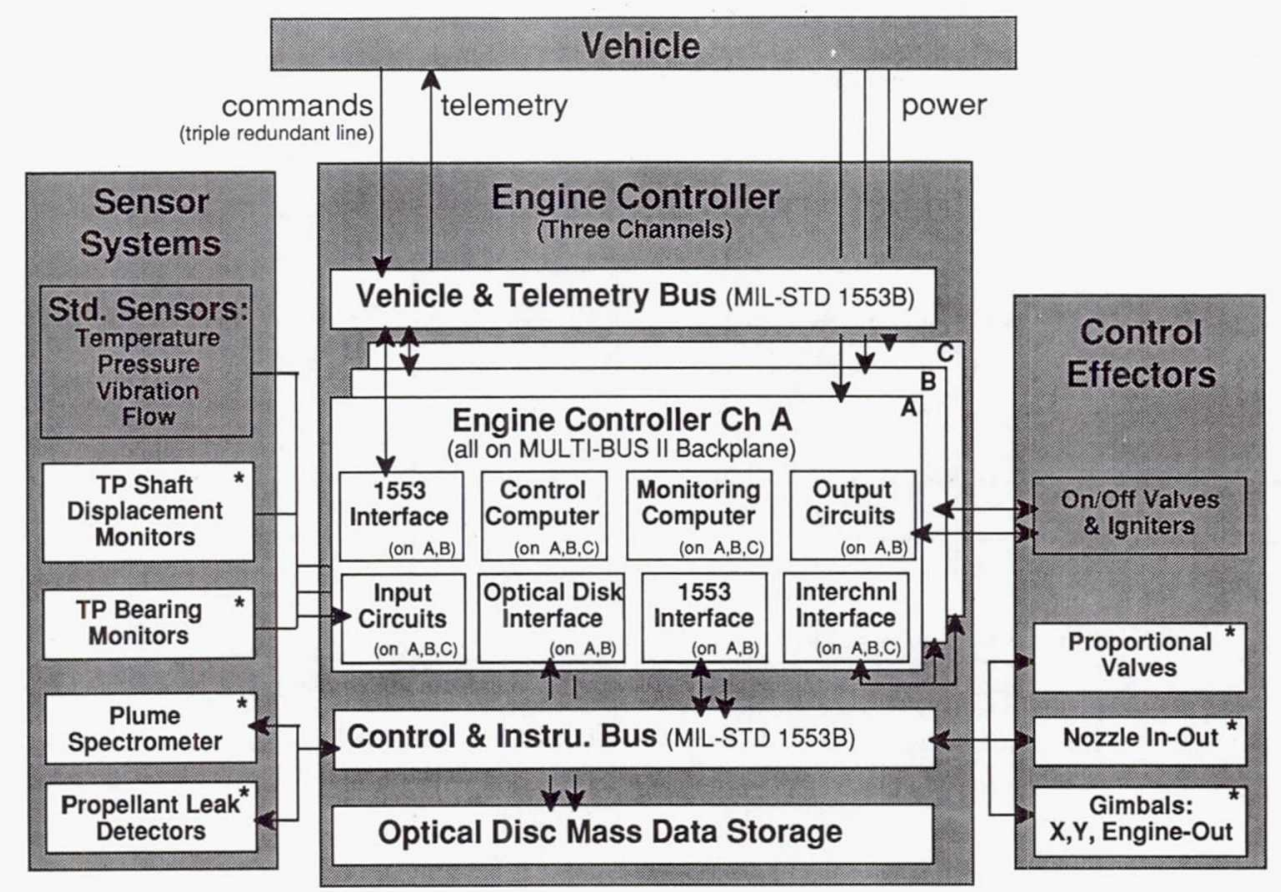

Figure 1. - Aerojet ICHM System Architecture

* These elements include pre-processing, sginal conditioning, or feedback circuits.

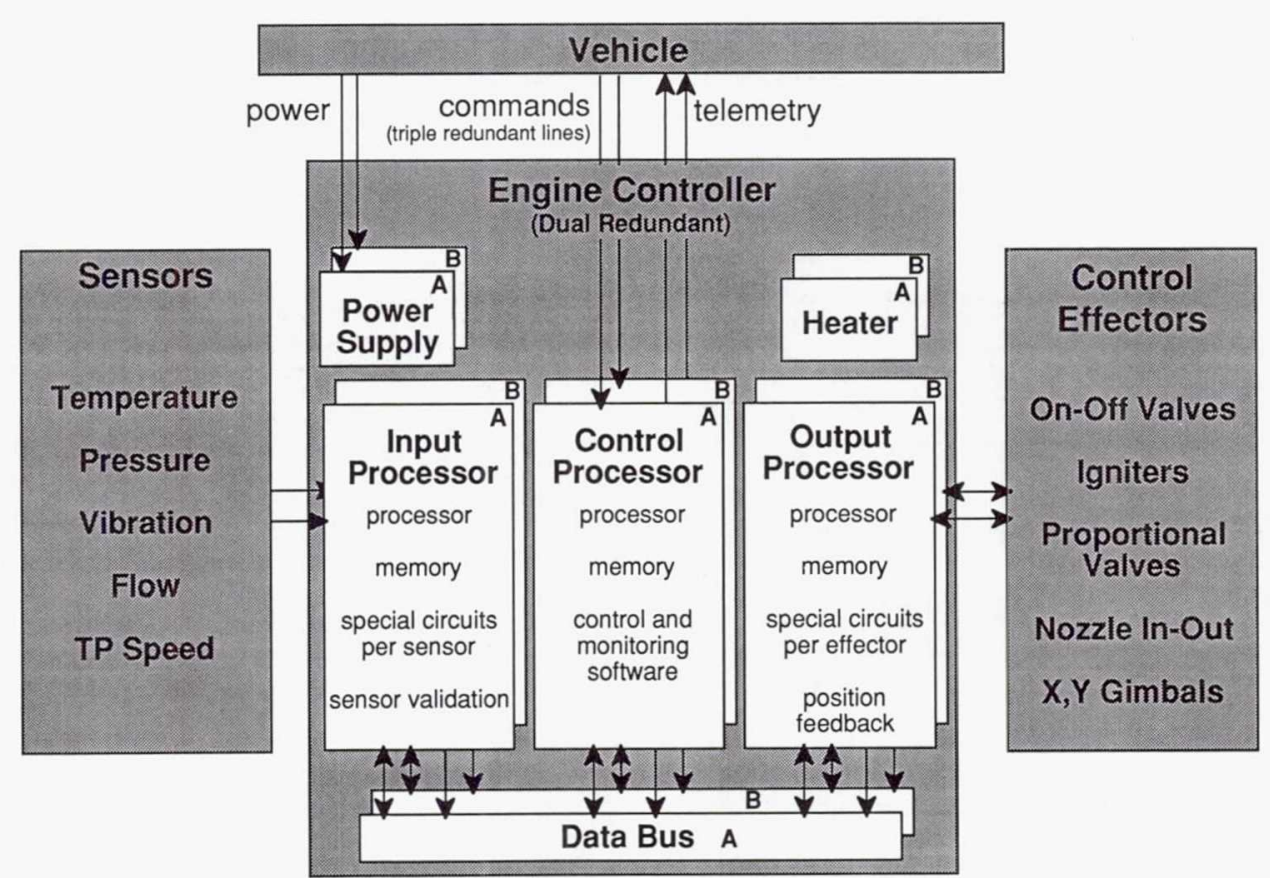

Figure 2. - Rocketdyne ICHM System Architecture 


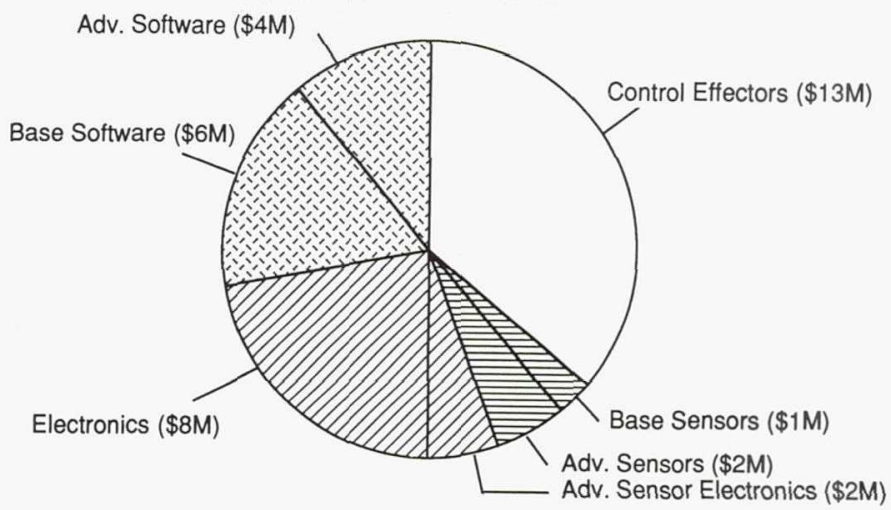

Figure 3. - Synthesized Cost Estimate

(Totals \$28M base $+\$ 8 \mathrm{M}$ for adv. elements)

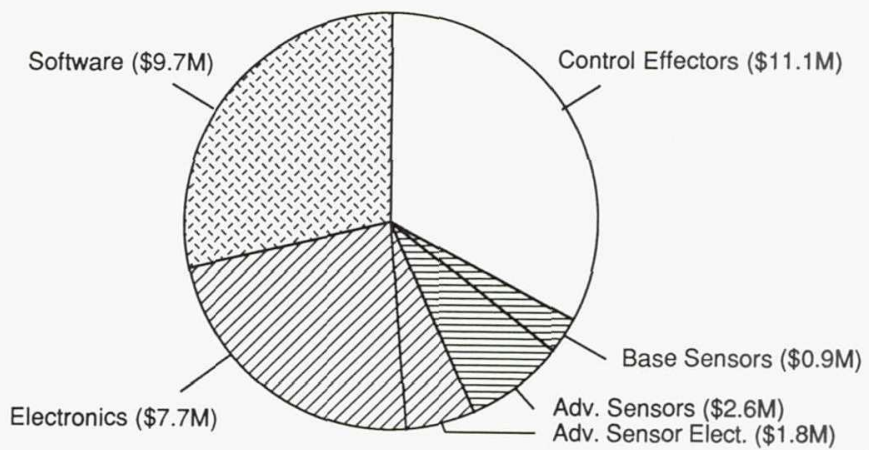

Figure 4. - Aerojet Cost Estimate (Totals $\$ 33.8 \mathrm{M}$ )

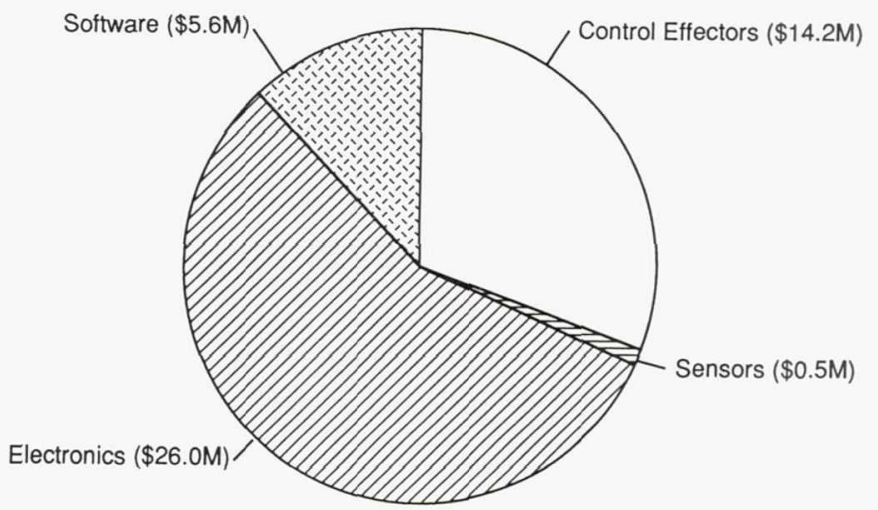

Figure 5. - Rocketdyne Cost Estimate (Totals $\$ 46.3 \mathrm{M}$ ) 
Public reporting burden for this collection of information is estimated to average 1 hour per response, including the time for reviewing instructions, searching existing data sources, gathering and maintaining the data needed, and completing and reviewing the collection of information. Send comments regarding this burden estimate or any other aspect of this collection of information, including suggestions for reducing this burden, to Washington Headquarters Services, Directorate for information Operations and Reports, 1215 Jefferson Davis Highway, Suite 1204, Arlington, VA 22202-4302, and to the Office of Management and Budget, Paperwork Reduction Project (0704-0188), Washington, DC 20503.

\begin{tabular}{|l|c|c|}
\hline 1. AGENCY USE ONLY (Leave blank) & $\begin{array}{r}\text { 2. REPORT DATE } \\
1991\end{array}$ & $\begin{array}{r}\text { 3. REPORT TYPE AND DATES COVERED } \\
\text { Technical Memorandum }\end{array}$ \\
\hline
\end{tabular}

4. TITLE AND SUBTITLE

Technology Readiness Assessment of Advanced Space Engine Integrated Controls and Health Monitoring

5. FUNDING NUMBERS

Marc G. Millis

WU $-593-12-11$

7. PERFORMING ORGANIZATION NAME(S) AND ADDRESS(ES)

National Aeronautics and Space Administration

Lewis Research Center

Cleveland, Ohio 44135-3191

8. PERFORMING ORGANIZATION REPORT NUMBER

E- 6584

9. SPONSORING/MONITORING AGENCY NAMES(S) AND ADDRESS(ES)

10. SPONSORING/MONITORING AGENCY REPORT NUMBER

National Aeronautics and Space Administration

Washington, D.C. 20546-0001

NASA TM - 105255

AIAA - 91 - 3601

11. SUPPLEMENTARY NOTES

Prepared for the Conference on Advanced Space Exploration Initiative Technologies cosponsored by AIAA, NASA, and OAI, Cleveland, Ohio, September 4 -6, 1991. Responsible person, Marc G. Millis, (216) 433 - 2425.

12a. DISTRIBUTION/AVAILABILITY STATEMENT

12b. DISTRIBUTION CODE

Unclassified - Unlimited

Subject Category 20

13. ABSTRACT (Maximum 200 words)

NASA Lewis Research Center contracted Aerojet and Rocketdyne to assess the Integrated Controls and Health Monitoring (ICHM) technologies that would enable hydrogen-oxygen rocket engines to be space-based, reusable, and descentthrottleable. The results of these assessments are synthesized to determine the minimum required ICHM functions and system elements, and to estimate the technology readiness and system cost. The minimum functions include preflight checks, tank head start, closed-loop thrust and mixture ratio control with red-line/shutdown safety monitoring, sensor validation/fault accommodation, and condition assessment. With the exception of the engine-dependent software and some of the advanced sensors, all the required elements have reached at least the technology readiness level of a laboratory demonstration. The total ICHM system readiness is at the level of a conceptual design. The estimated cost to provide to provide a minimum ICHM system ready for demonstration on an engine system testbed is estimated to be $\$ 30$ to $\$ 45$ million over six years.

14. SUBJECT TERMS

Rocket engine; Rocket engine control; Rocket engine health monitoring; Orbit transfer vehicle; Space-based rocket engine; Technology readiness assessment; Space exploration initiative

17. SECURITY CLASSIFICATION OF REPORT

Unclassified

18. SECURITY CLASSIFICATION
OF THIS PAGE
Unclassified

Unclassified

\section{SECURITY CLASSIFICATION OF ABSTRACT Unclassified}

15. NUMBER OF PAGES 16

16. PRICE CODE $\mathrm{A} 03$

20. LIMITATION OF ABSTRACT 